\title{
RELENDO “MORTE DAS CASAS DE OURo Preto"
}

http://dx.doi.org/10.11606/issn.2237-1184.v0i34p185-196

Sérgio Alcides ${ }^{I}$

\section{RESUMO}

Leitura do poema "Morte das casas de Ouro Preto", de Carlos Drummond de Andrade, publicado em jornal em 1949 e depois no livro Claro enigma, de 1951. Análise de aspectos formais e ênfase na situação do sujeito, com relação à enunciação e ao enunciado.

\section{ABSTRACT}

A reading of the poem "Morte das casas de Ouro Preto" ("Death of the houses of Ouro Preto"), by Carlos Drummond de Andrade, first published in a newspaper in 1949 and later included in his 1951 collection Claro enigma ("Clear Enigma"). Analysis of poetic form with an emphasis on the situation of the Self, with respect to the enunciation and the utterance.

\section{PALAVRAS-CHAVE:}

Poesia brasileira; Carlos Drummond de Andrade;

Forma poética; Sujeito.

\section{KEYWORDS}

Brazilian poetry; Carlos Drummond de Andrade; Poetic form; Self.

I Universidade Federal de Minas Gerais, Belo Horizonte, Minas Gerais, Brasil. 


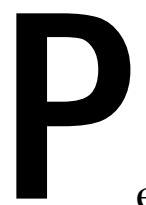

ermanece, desgastando-se, o horizonte de uma antiquíssima sentença: "Assim como a pintura, é a poesia". Na concepção original, o poema seria imagem que fala (cf. MARKIEWICZ, 1987, p. 537). Em "Morte das casas de Ouro Preto", de Carlos Drummond de Andrade, dá-se o contrário (ANDRADE, 2002, p. 277-9). O tempo passa, e a permanência não pode ser senão uma espécie de mudança. As estâncias compõem na página uma paisagem imaginária. Mas um profundo silêncio vem pousar sobre as palavras, com a chegada, no fim, de "uma colcha de neblina" (verso 81), que traz a interrupção e conta "por que mistério / o amor se banha na morte" (vv. 83-4). No instante da última sílaba, é como se a duração de mais de oitenta versos fosse cancelada; tudo se ressignifica e se atualiza diante do leitor, com a simultaneidade aparente de uma tela, que é poesia silente.

Decisiva para isto é a inesperada entrada, no enunciado, do sujeito da enunciação: "Sobre a cidade concentro / o olhar experimentado" (vv. 64-5). Só a partir daí ele é mais nitidamente avistado no texto, paleta e pincel na mão, dizendo-se "douto no assunto" (v. 67). O mistério final é contado a ele, não ao leitor. $\mathrm{O}$ tempo verbal presente leva a presumir que a duração coincide com a apreensão do arcano. A natureza pública da poesia convida à busca de um acesso através da leitura, mas sem nenhuma garantia além da declaração da experiência, como lastro e legitimidade da escrita e sua fruição.

A regularidade formal parece aspirar àquela translucidez clássica de que é revestido o material a ser destacado da temporalidade imediata pela poesia. São doze estrofes ao todo, cada uma com sete versos. A metrificação pela tônica da sétima sílaba lhes dá o aspecto compacto com que se enfileiram, cúbicas $-7 \times 7$. Nelas se dobra sobre si mesmo o algarismo cosmológico por excelência, com suas tantas faces. Seria de se esperar que a estruturação das formas manifestasse, através do apuro artístico, uma tradução da imagem antes presente na mente do poeta, como um selo abstrato de uma verdade originária. Por meio desse halo ordenador o poema se habilitaria a viajar até a sempiternidade - o aevum da escolástica medieval, que é o plano situado entre o tempo e a eternidade, por ser de ambos partícipe. Ingressaria, dessa maneira, no domínio dos seres criados que, tendo princípio, não têm fim, como os anjos e os santos celestiais. Acima, o Incriado afiançaria toda a atividade, que em Si mesmo resumiria, como leitor absoluto e razão última da poesia.

Entretanto, há muito que a autoridade de tal fiador foi posta em questão: o amplo esquema teológico, pensado como transcendente ao 
movimento da história, caiu por terra. "O chão começa a chamar / as formas estruturadas / faz tanto tempo" (vv. 29-31). Sob a chuva incessante que ameaça as construções antigas, trata-se do desmantelamento dos esforços humanos, não de sua sublimação. Desfaz-se o desígnio que impunha forma à matéria, espiritualizando-a. "Que se incorporem as árvores / hoje vigas!" (vv. 33-4). São as casas que "morrem" pela ação do mau tempo e se abandonam a um aniquilamento inelutável.

O tema não deixa de envolver um aspecto metapoético: o esquema clássico é evocado apenas para ser reduzido à mesma incorporação, pela qual se desfaz tudo aquilo que é fabrico, feitura, poiesis. Entretanto, isso não se explicita antes de um jogo, pelo qual o leitor é como que capturado para um ambiente específico, mais propício à consideração que direciona também a experiência estética para o horizonte escatológico mais diretamente abordado. Inicialmente, o trabalho formal cultiva a expectativa da transparência clássica. As cinco primeiras estrofes apresentam-se íntegras, autocontidas, com a exposição do tema, que começam a desenvolver. Logo se observa um deslizamento, bem na metade do poema, traspassando a separação entre a sexta e a sétima estrofes. Um enjambement faz o "fino dardo da chuva" (v. 42) se prolongar até o bloco seguinte, por ser uma chuva "mineira, sobre as colinas" (v. 43). A enxurrada começa a arrastar a forma. Outro acidente acontece entre a oitava e a nona estrofes, separadas por vírgula e não ponto: as velhas casas "vão na geada,// enquanto se espalham outras" (vv. 56-7). Até se abrir o barranco sem pontuação entre as duas últimas, quando se reitera um verbo determinante: "dissolver".

São duas as suas ocorrências. A primeira é mais oblíqua, reflexiva:

\author{
[...] É tempo \\ de fatigar-se a matéria \\ por muito servir ao homem, \\ e de o barro dissolver-se. (vv. 22-5)
}

Também a matéria se fatiga, na poesia de Drummond, além das retinas. Mas não a matéria em geral, as coisas materiais, que ocupam lugar no espaço e têm massa: o caso é sobre a matéria já modelada pelo ser humano, menos presa ao volume do que à função, e posta a serviço deste, que é ele próprio barro animado. A razão dissolvente está bem implícita na passagem, recalcada nas paredes da poesia. Infiltra-se aí, com a aproximação dos termos "homem" e "barro", mas logo escoa, mal percebida, porque a paisagem do poema ainda é duração, que mal começou. A leitura não a expõe sem zurzir o texto, fustigar os versos. Só depois da segunda ocorrência, com o olhar experimentado, o leitor pode 
constatá-la post facto, ao reler o trecho como quem pisa na lama de uma região já assolada. Porque, ao ressurgir, o verbo se mostra em ação direta:

\author{
A morte baixou dos ermos, \\ gavião molhado. Seu bico \\ vai lavrando o paredão \\ e dissolvendo a cidade. (vv. 75-8)
}

O sujeito da dissolução é a morte. A poesia está a ponto de se mudar em pintura, na mente do leitor/releitor. Também o triste vocábulo é reiterado para possibilitar a conversão, no fim: é a última palavra, solução e rima (bem a propósito, para "chuva forte", vv. 82 e 84).

A indesejada vem do alto, de um céu deserto ("baixou dos ermos"), sob a espécie de uma metáfora ("gavião molhado"). Conclui-se que seu ofício é a rapina, o roubo da vida, mas também as atividades associadas ao verbo "lavrar": seja a lavoura que revolve o terreno a ser cultivado, seja a escavação que minera o subsolo. Que pretende ela colher ou extrair, ao final de seu labor que nunca acaba? De fato, dois gerúndios bordejam o lanho aberto na página pelo bico mortífero: "lavrando" e "dissolvendo".

No poema que estamos analisando, há mais coisas para ler do que palavras. Tudo reclama um intérprete: até no espaço em branco pode haver significação discutível. As estâncias são como as coisas, que "sempre cambiam/ de si, em si" (vv. 27-8). Ali plantadas na página, "pareciam eternas" (v. 12), mas também se dissolvem. A transparência inicial da forma desmorona aos olhos do leitor, como uma vidraça que só se torna perceptível ao rachar e, logo em seguida, ir ao chão, estilhaçada. Experimenta-se, no decorrer da poesia, uma tomada de consciência. A frustração das expectativas se impõe entre os assuntos mais profundamente elaborados no texto, sob a superfície pictórica do tema.

Há mais coisas a ler do que palavras, mas mesmo estas extrapolam a mera dicotomia entre o significado e o significante. "Rótula", por exemplo, ou "caliça": quem hoje dispensaria o dicionário diante de tais enigmas? Outros termos arquitetônicos se sucedem. O leitor, fazendeiro do ar, procura em vão no seu apartamento as "esteiras de forro", os "cachorros de beiral" e os "paços de telha-vã" mencionados no texto. Seria igualmente insano querer encontrar, nas casas que desabam sob a chuva de Ouro Preto, um living-room ou o closet. O poeta selecionou termos velhos, poídos como a fazenda muito antiga, que ficou guardada. Podemos correr até os grandes livros do passado, em busca de socorro. Moraes Silva chega de 1789 e nos conta que a "rótula" é uma "obra de madeira com gelosias para tapar as janelas" (SILVA, 1789, vol. 2, p. 358). "Gelosias"? O Novo dicionário, que é de 1806, explica que são "fasquias atravessadas e pregadas em um 
caixilho, com que se cobrem as janelas" (ROLLANDIANA, 1806, s. p.). "Fasquias"? Pelo que nos diz Caldas Aulete, em 1881, seriam "travessas de madeira que se cruzam entre si" (AULETE, 1881, vol. 2, p. 1.577). Os "pdfs" cheiram a mofo! Só mesmo o Houaiss online, em tom de arqueologia, rompe a acepção indevassável: "rótula" ou "gelosia" é aquela "grade de ripas, de malha pouco aberta, que guarnece algumas janelas a fim de impedir que a luz e o calor excessivos penetrem no interior da casa, e que este seja devassado da rua" (HOUAISS e VILLAR, 2001). Porém não há mais nada a devassar no interior das moradias em declínio: "cai a chuva/ sobre rótula e portão" (DRUMMOND, 2002, vv. 13-14). É como se os furos formassem o próprio crivo do tempo:

\author{
Vai-se a rótula crivando \\ como a renda consumida \\ de um vestido funerário. (vv. 15-17)
}

Pela comparação fúnebre, a peça antiquada envolve os restos mortais da experiência, a matéria abandonada pela vida que se foi. Passado o fausto dos melhores dias, as edificações "menos rudes que orgulhosas" (v. 9) finalmente se humilham no anacronismo que as dissolve:

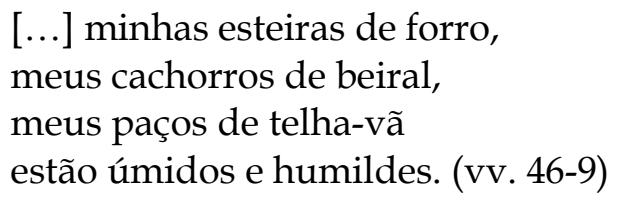

É o chamado da terra: "humilde remete a humus, chão" (ARRIGUCCI JR., 1990, p. 132). Já faz pouca diferença se o telhado está sem forro por dentro ("telha-vã") ou tem esteira; e se, por fora, está "sem eira nem beira" ou assenta em viga ornamental (antes conhecida como "cachorro"). Mais do que o significado das expressões datadas, mais até do que a distinção social que nelas se inscrustava em outras épocas, importa nessa poesia a sua significação esboroada. O poema é escrito com palavras, mas algumas delas caíram em desuso, e estão vencidas. É necessário "ler", nelas, também - se não principalmente - o desgaste, a obsolescência com que "se deixam morrer" (DRUMMOND, 2002, v. 61), assim como as casas que precariamente descrevem e qualificam.

Essa última passagem - situada na sétima estância, a meio-caminho do fim - representa uma etapa da lenta insinuação do sujeito, até a sua irrupção em primeira pessoa, no último quarto. A princípio, ele é só uma interjeição, um “ai!” (v. 12), à maneira de Cecília Meireles. Os imperativos da quinta estrofe - "Que se incorporem as árvores" (v. 33) e "Volte o pó/ a ser pó" (vv. 34-5) - são impessoais: exprimem a convocação telúrica fatal. 
Mas, na sexta, as locuções interjetivas manifestam um teor de subjetividade: "Como chove, como pinga" (v. 37), "Como bate, como fere" (v. 39). É apenas uma voz, por enquanto. Mas é uma voz entoada ao ritmo da chuva, tedioso e maçante, na divisão mais banal possível do verso heptassilábico, em dois idênticos hemistíquios anapésticos (aproveite o leitor que já está com o dicionário aberto):

Sobre o tempo, sobre a taipa (v. 1)

só a chuva monorrítmica

sobre a noite, sobre a história (v. 20)

Vão no vento, na caliça, no morcego, vão na geada (vv. 55-6)

sem as vermos fenecer (v. 59)

Sobre a ponte, sobre a pedra (v. 79)

O ritmo da perda pontua a voz do perdedor. Porque é esta a condição implicada nos possessivos já citados: "minhas casas", "minhas paredes" etc. São novas interjeições, agora ligadas à posse cancelada, e marcadas pelo selo pronominal.

Mas a presença do sujeito só se completa na antepenúltima estrofe, ao preço de uma ruptura. Antes, sendo apenas uma voz da enunciação, ele preserva a coesão que é forçado a romper para ingressar no enunciado. Ao se ver representado na narrativa, já se mostra dúplice: a voz do "eu" e ele, o "eu" referido. Os verbos no modo indicativo evidenciam tal composto, aquilo que faz, aquilo que o constitui e aquilo que percebe: "concentro" (v. 64), "perdi" (v. 68) e "vejo" (v. 69). No bloco seguinte, o leitor acaba incluído na problemática subjetiva, capturado por uma incômoda primeira pessoa do plural: "em nós" (v. 73), “à nossa roda" (v. 74). No fim, a fusão retorna ao singular, reduzida à partícula átona, passiva, que recebe a lição da paisagem: a sentença "me conta por que mistério [...]" (v. 83) já tem o valor de nos contar alguma coisa passível de algum modo poético de conhecimento. Ao começarmos a releitura, já estamos também mais doutos.

A técnica de antecipação oblíqua seguida de consumação abrupta não se restringe ao "eu": incide ainda sobre a força que promete reduzi-lo a nada. Notamos, atrás, como ela própria se afirma, de repente, como sujeito da dissolução, no mesmo trio de estâncias que arrematam a poesia e promovem seu efeito de pintura. Em partes anteriores, desde o princípio, 
as casas "morrem" continuamente (vv. 7, 21, 22, 60, 61) - quando não por meio do verbo aplicável, em imagens de decesso iniludível: "vão-se" (v. 25), “lá vão" (v. 50), "vão no vento" etc. (vv. 55-6), "ei-las sumindo-se no $\operatorname{ar}^{\prime \prime}$ (v. 60). Só com a consumação crucial da primeira pessoa se pode enunciar o nome da "coisa pegajosa" que o "eu" avista (v. 69): “Não basta ver morte de homem / para conhecê-la bem" (vv. 71-2). Pouco adiante, o que era objeto direto passa à ação: "baixou” (v. 75), "vai lavrando" (v. 77), "dissolvendo" (v. 78). Consummata est, pode-se dizer: "está consumada" parafraseando as palavras derradeiras de Cristo, na cruz (João 19, 30).

A dissolução se consuma, mas a poesia, não. A leitura de um poema exigente são mil outras releituras, em diferentes contextos, com motivações diversas, presumivelmente sem fim. E o mais importante quase sempre escapa à lógica do comentário (que pode estar certo ou errado, ser verdadeiro ou falso), por depender do gume falível da interpretação (que não pode almejar mais que a plausibilidade, a pertinência ou a persuasão) (cf. CANDIDO, 2006, p. 27-36). No poema que temos diante dos olhos, é o sujeito e a morte têm traços em comum. Os dois parecem vir do alto, distanciados, e submetem a cidade: ele pela agudeza, ela pela dissolução (DRUMMOND, 2002, vv. 65 e 78). Seria cabível dizer que "Morte das casas de Ouro Preto" explora (entre outras coisas) uma afinidade perturbadora entre a poesia e a escatologia, como ciência dos "últimos fins". Mas aí já se pula uma linha entre o comentário acurado e a interpretação sempre aberta ao debate e ao dissenso.

A afinidade é sugerida, sobretudo, pelas imagens pintadas nas duas penúltimas estrofes. O sujeito e a morte são pássaros até certo ponto assemelhados. Ambos pairam acima da paisagem, "circunvoando na calma" (v. 70), "sobre a cidade" (v. 64). Ele é um falconídeo de "agudo olhar afiado" (v. 66). Quanto a ela, falta dizer que "gavião" é mais uma palavra encostada e enferrujada, pelo menos em suas acepções mais sugestivas: é a "extremidade do gume de alguns instrumentos", ou a "ponta afiada de um formão" e, como brasileirismo, a "parte curva e cortante de uma podadeira, de uma foice" (HOUAISS e VILLAR, 2001, "gavião"). Está molhado, mas nem por isso é menos cortante. Afinal, é também a matadora chuva - como o poeta, sabidamente - "mineira". Mas o que seria uma tal chuva, capaz de desmanchar a forma de duas estrofes na página? O estereótipo atrás do qualificativo insinua uma hipótese: seria aquela que mina a terra com amargura ambivalente, quase afetiva, escavadora paciente como o ressentimento, tão esquiva quanto penetrante, imperial muito embora discreta, conquistadora ensimesmada. "Mil outras brotam em nós", diz o mineiro (v. 73), como quem exemplifica a ambivalência: a morte nos mata mil vezes, em vida? Ou nós mesmos a 
engendramos, com o viver? Esse ir morrendo é a experiência da vida? Ou é a experiência do viver que se torna portadora da morte?

Tais interrogações se contam entre os efeitos escatológicos da poesia. Foi na morte que o poeta afiou o "olhar experimentado" (v. 65), como confessa, entre parênteses: “(Quantos perdi me ensinaram.)” (v. 78). É outra frase enviesada, por vir o ensinamento, antes, da perda, não dos entes que foram perdidos. Logo, já se sabe quem foi, de fato, a professora... A menos que, também neles brotando mil outras, transmitissem a quem os perderia, junto com o afeto, essa educação sinistra. Seja como for, o mero aprendizado implica para o aluno um desprendimento de seu meio original, limitado, porém, pela disparidade irredutível entre ele e a morte. Ela não pertence em absoluto ao mundo em dissolução, enquanto o "eu" vive imerso no fluxo do tempo e é quase tão vetusto quanto as casas fustigadas de que se faz herdeiro inoperante e elegíaco. Sobretudo, na duplicidade de seu pertencimento distanciado, o poeta não pode ignorar que seu fado é também voltar "a ser pó pelas estradas" (v. 35).

Nessa condição, o sujeito habita o "país das remembranças" (v. 38), onde a chuva desce com expressões de outros tempos, "às canadas" (v. 36). As casas moribundas são igualmente doutas: "viram fugir o ouro" (v. 4), "viram finar-se o reino" (v. 5) e, como o leitor de poesia, que muito relê, "viram, reviram, viram" (v. 6). São "casas honradas, / onde se amou e pariu" (vv. 51-2); nelas o viver nutriu esperanças e projetos, "guardou moeda" (v. 53). A frustração das expectativas, na leitura, alegoriza esse movimento da vida que se impõe aos viventes. Contemplá-lo na paisagem e na página se torna um cuidado constitutivo do sujeito. É o mistério de perdas assimiladas, como uma espécie de vazio substancial, que se revela com a consumação do poema como pintura: "o amor se banha na morte" (v. 84). Folheando o mesmo livro, Claro enigma, encontram-se mais sinais do mesmo colapso entre a lembrança como reiteração dolorosa da perda e o apego subjetivo à experiência e às expectativas irresgatáveis; seu maior emblema é o poemeto da "Memória": "Amar o perdido..." (ANDRADE, 2002, p. 252).

A leitura renitente vai elaborando a experiência, separando os elementos que traz à tona, desfazendo a indistinção entre o revestimento do tema e o assunto que se oculta mais a fundo, na argamassa mesmo da poesia. A pintura mostra a dissolução da paisagem afetiva, em estâncias que se desmancham pela ação do tempo e da chuva. Mas o que se experimenta em profundidade é uma aproximação estética ao "conhecê-la bem" do verso 72 - ao conhecimento da morte, tão elusivo, ainda que o saibamos fatal.

Em "Morte das casas de Ouro Preto", a estiagem final interrompe a ação da chuva, que se paralisa no ar como no texto. Uma "colcha de 
neblina" (v. 81) recobre a cidade, o sujeito e a até a poesia - seja como vestígio, seja como metonímia: a "cambraia de Nize". Poderia haver melhor designação para o ideal da forma clássica? É o tecido bem fino, translúcido, que se oculta por cima do que reveste, para assim melhor expor, com a elevação do ideal, o corpo que oferece à fruição. Seria, no dizer de Petrarca, a própria "velatura de fingimentos" com que o poeta enaltece a verdade das coisas - sub velamine figmentorum (apud KANTOWORICZ, 1961, p. 355). Porém, despida a cambraia, rompe-se o encanto e a trama. A umidade agora cai sobre o pano, que resta. A pastorinha da Arcádia já se foi faz tempo; deixou para trás, além da roupa íntima, um detalhe de ortografia preservada: a letra $z$ de seu nome, que hoje se escreve (?) com $s$.

O releitor retorna ao dicionário e aprende que o termo tinha origem toponímica: vinha de Cambrai, cidade do Norte da França "onde se produzia e de onde se exportava esse tipo de tecido" (HOUAISS e VILLAR, 2001). A transparência que espiritualiza sugeriu neste outro continente uma acepção a mais, alusiva não ao linho e sim à cana. Fica-se na dúvida, se ainda existe no país um botequim onde se possa pedir um bom gole de "cambraia".

"Toda história é remorso", diz o último verso anterior a "Morte das casas de Ouro Preto", no ordenamento poético de Claro enigma, de 1951; é da quinta parte da sequência "Estampas de Vila Rica" (ANDRADE, 2002, p. 277).

No livro que se inicia com o poema "Dissolução" (Idem, ibidem, p. 247), o poema aqui relido pertence à quarta das seis seções, intitulada "Selo de Minas". Como grande parte da obra poética do autor, foi publicado antes na imprensa cotidiana: saiu no Correio da Manhã de 4 de setembro de 1949, um domingo (Idem, 1949, 3, p. 1). Na primeira página do caderno dedicado à cultura, vinha acompanhado de fotografia (com a legenda "Ouro Preto vista do Morro das Queimadas"), e diagramado acima de um texto em prosa sem assinatura, que começava assim:

Protejamos Ouro Preto - Numerosas casas coloniais de Ouro Preto, a bela e gloriosa cidade mineira, estão desaparecendo, sob a ação do tempo e das grandes chuvas. Construções singelas, de taipa, não resistem à ação desagregadora das águas. Faltam à cidade recursos para obras de restauração e conservação. (CORREIO DA MANHÃ, 1949, p. 1)

É possível que a redação fosse do próprio Drummond, mas a paginação deixava margem à dúvida, e o teor impessoal dispensava a 
autoria. Trata-se de uma notícia: um grupo de senhoras resolvera angariar fundos em benefício da cidade mineira, a serem remetidos para o Serviço do Patrimônio Histórico e Artístico Nacional (SPHAN). Havia uma campanha em curso, desde os estragos causados por chuvaradas recentes. Drummond não era o único poeta engajado; Augusto Frederico Schmidt publicou um artigo em sua coluna semanal (SCHMIDT, 1949, p. 2); Manuel Bandeira também aderiu, com o poema "Minha gente, salvemos Ouro Preto", depois incluído em seu livro Opus 10 (BANDEIRA, 1949, p. 1; BANDEIRA, 1974, p. 303-4). Já se observou que, nessa época, a preservação da antiga Vila Rica tinha se tornado "um grande tópos da poesia brasileira" (OHATA, 2011, p. 309).

Anos depois, Drummond comentou em sua coluna, no mesmo jornal, a morte de Alberto da Veiga Guignard. Era outro pintor de Ouro Preto - ou "poeta pintor", como é chamado na homenagem. Sua obra apresentaria "uma organização poética de ritmos requintados", que seria "específica da poesia". O necrológio elabora brevemente dois aspectos de tal especificidade:

\begin{abstract}
Nunca, para meu gosto, poesia e pintura se fundiram tanto na arte brasileira quanto nas telas de Guignard, em que a visão lírica do artista não é um elemento voluntário e adicional, mas a determinante da concepção. Pintura e desenho de Guignard produzem-nos a euforia do conhecimento poético das coisas, refiguradas mais do que transfiguradas, pois não perderam a realidade, mas revelaram seus traços íntimos, sua tessitura sensível, ao mesmo tempo que sugerem uma forma de poema legível através dos valores plásticos. (ANDRADE, 1962, p. 6)
\end{abstract}

O primeiro aspecto é a "visão lírica do artista", intrínseca à composição. $\mathrm{O}$ segundo é o "conhecimento poético", capaz de revelar o íntimo das coisas, sem desprendê-las do real. A figuração pictórica não transfigura seus objetos: refigura o entorno tal como é visto pelo artista: "Era a poesia que ele carregava em si e que o embalou a vida toda, fazendo-o viver ao mesmo tempo em dois mundos distintos" (Idem, ibidem).

Um terceiro aspecto se acrescenta agora, sobre a natureza particular do sujeito, ser dual, diferente dos demais. O contato com sua arte propicia ao público o transporte até o mundo refigurado só dele.

Como paisagem de letras, "Morte das casas de Ouro Preto" lembra os vários quadros que ao mesmo casario dedicou Guignard. Entretanto, neles, a impressão de eternidade parece restituída, enquanto o poema se inicia justamente pelo desmanchar-se dela. O elogio de Drummond ao pintor pode ser tomado como esclarecimento indireto sobre sua própria poética, mas caberia uma advertência. Talvez suas palavras disfarcem, no 
fundo, uma confissão e um lamento: na refiguração do real, Guignard ainda encontra a pastora por dentro da lençaria transparente.

Ainda assim, a sugestão de um "conhecimento poético das coisas" parece aplicar-se ao plano escatológico de "Morte das casas de Ouro Preto". Não como um postulado, que o poeta dificilmente respaldaria (para ele, não se conhece uma coisa sem perdê-la antes; a refiguração lhe desfigura o mundo). Mas como um impulso à ficção da poesia.

\section{Referências bibliográficas}

ANDRADE, Carlos Drummond de. "Criança \& poeta". Correio da Manhã. Rio de Janeiro, 27 jun. 1962 (1º caderno, p. 6).

AndRADE, Carlos Drummond de. "Morte das casas de Ouro Preto". Correio da Manhã. Rio de Janeiro, 4 set. 1949 (3º caderno, p. 1).

ANDRADE, Carlos Drummond de. Poesia completa. Edição preparada por Gilberto Mendonça Teles. Rio de Janeiro: Nova Aguilar, 2002.

ARriguCCI JR., Davi. Humildade, paixão e morte. A poesia de Manuel Bandeira. São Paulo: Companhia das Letras, 1990.

AUlETE, Francisco Júlio Caldas. Dicionário contemporâneo da língua portuguesa, feito sobre um plano inteiramente novo. Lisboa: Imprensa Nacional, $1881,2 \mathrm{v}$.

BANDEIRA, Manuel. "Minha gente, salvemos Ouro Preto!" Correio da Manhã. Rio de Janeiro, 11 set. 1949 (3 caderno, p. 1).

BANDEIRA, Manuel. Poesia completa e prosa. Edição organizada pelo autor. Rio de Janeiro: Aguilar, 1974.

CANDIDO, Antonio. O estudo analítico do poema. 5. ed. São Paulo: Humanitas, 2006.

CORReio da Manhã. "Protejamos Ouro Preto". Correio da Manhã. Rio de Janeiro, 4 set. 1949 ( $3^{\circ}$ caderno, p. 1).

HOUAISS, Antonio; VILLAR, Mauro de Salles. Grande dicionário Houaiss da lingua portuguesa. Rio de Janeiro: Instituto Antonio Houaiss: Objetiva, 2001. 
KANTOROWICZ, Ernst H. “The Sovereignty of the Artist. A Note on Legal Maxims and Renaissance Theories of Art" (1961). In: Selected Studies. Nova York: J. J. Augustin, 1965, p. 352-65.

MARKIEWICZ, Henryk. "Ut pictura poesis... A History of the Topos and the Problem". New Literary History. Baltimore, n. 3, vol. 18, pp. 535-58, primavera de 1987.

OHATA, Milton. "Notas de edição". In: ANDRADE, Carlos Drummond de. Passeios na ilha. Edição preparada por Augusto Massi e Milton Ohata. Posfácio de Sérgio Alcides. São Paulo: CosacNaify, 2011, p. 291-336.

Rollandiana. Novo dicionário da língua portuguesa. Lisboa: Tipografia Rollandiana, 1806.

SCHMIDT, Augusto Frederico. "Alguém está morrendo". Correio da Manhã. Rio de Janeiro, 31 ago. 1949 (1 ${ }^{\circ}$ caderno, p. 2).

SILVA, Antônio de Moraes. Dicionário da língua portuguesa, composto pelo Pe. D. Rafael Bluteau, reformado e acrescentado por... Lisboa: Simão Tadeu Ferreira, 1789.

Sérgio Alcides é professor da Faculdade de Letras da Universidade Federal de Minas Gerais. É autor de, entre outros livros, Estes penhascos: Cláudio Manuel da Costa e a paisagem das Minas, 1753-1773 (2003).

Contato: sergioalcides@ufmg.br

ORCiD: https:/ / orcid.org/0000-0002-0247-4993

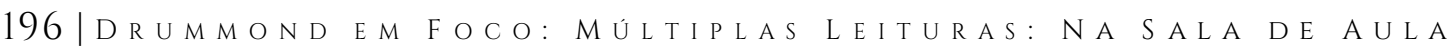

